\title{
Analisis Pengaruh Kualitas Produk, Harga, Promosi dan Distribusi Terhadap Kepuasan Konsumen Produk Air Mineral Kemasan Adeni Di Kabupaten Pamekasan
}

\author{
Ainol Yakin 1 ) \\ 1) Institut Agama Islam Negeri Madura, Pamekasan, Indonesia \\ Corresponding author: 1234ainolyakin@gmail.com
}

\begin{abstract}
:
In the midst of an increasingly difficult economic situation, there is a lot of competition in various fields of life, one of which is competition in the business world. Many companies are competing with each other to get their market share. This research was conducted to determine the effect of product quality, price, promotion and distribution which has a dominant influence on the consumer satisfaction of Adeni's products in Pamekasan Regency. The total sample size was 104 consumers. The variables in this study consisted of independent variables including product quality (X1), price (X2), promotion (X3) and distribution (X4); The dependent variable is customer satisfaction (Y). Based on the results of data analysis and discussion, the conclusion of this study is that simultaneously, product quality, price, promotion and distribution (independent variables) have a significant effect on job satisfaction (dependent variable) Adeni Products in Pamekasan Regency. The results showed that simultaneously, product quality, price, promotion and distribution had a very significant effect on teacher performance, as evidenced by the calculated $F$ value of 3.556 with a significance level of 0.002 (less than 0.05). Partially, Product Quality, Price, Promotion and Distribution have a significant influence on Customer Satisfaction of Adeni Products in Pamekasan Regency, this is evidenced by the $t$ value of each independent variable, namely: product quality, the $t$ value is 4,719 with a significance level of $4,719.0 .003$, the value of the $t$ value is 2.351 with a significance level of 0.001 , the promotion of the $t$ value is 3.113 with a significance level of 0.004 and the distribution of the $t$ value is 3.063 with a significance level of 0.003 (less than 0.05 ). Thus, it can be said that all independent variables partially have a significant effect on Customer Satisfaction of Adeni Products in Pamekasan Regency.

Keywords: Product Quality, Price, Promotion, Distribution and Customer Satisfaction.
\end{abstract}

\begin{abstract}
Abstrak:
Di tengah keadaan perekonomian yang semakin sulit menyebabkan banyak terjadi persaingan di berbagai bidang kehidupan, salah satunya persaingan dalam dunia bisnis. Banyak perusahaan yang saling berlomba-lomba untuk mendapatkan pangsa pasarnya. Penelitian ini dilakukan untuk mengethui pengaruh kualitas produk, harga, promosi dan distribusi yang mempunyai pengaruh dominan terhadap terhadap Kepuasan Konsumen Produk Adeni di Kabupaten Pamekasan dengan jumlah sampel penelitian sebanyak 104 orang konsumen. Variabel dalam penelitian ini terdiri dari variabel bebas meliputi kualitas produk (X1), harga (X2), promosi (X3) dan distribusi (X4); Variabel terikat kepuasan konsumen (Y). Berdasarkan hasil analisis data serta pembahasan, maka kesimpulan penelitian ini adalah secara simultan, kualitas produk, harga, promosi dan distribusi (variabel bebas) mempunyai pengaruh yang signifikan terhadap kepuasan kerja (variabel terikat) Produk Adeni di Kabupaten Pamekasan. Hasil penelitian menunjukkan bahwa secara simultan, Kualitas Produk, Harga, Promosi dan Distribusi mempunyai pengaruh yang sangat signifikan terhadap kinerja guru, dibuktikan dengan nilai $\mathrm{F}$ hitung adalah sebesar 3.556
\end{abstract}


dengan tingkat signifikansi sebesar 0,002 (lebih kecil dari 0,05). Secara parsial, Kualitas Produk, Harga, Promosi dan Distribusi mempunyai pengaruh yang signifikan terhadap terhadap Kepuasan Konsumen Produk Adeni di Kabupaten Pamekasan, Hal ini dibuktikan dengan nilai t hitung masing-masing variabel bebas yaitu : kualitas produk nilai t hitungnya sebesar 4.719 dengan tingkat signifikansi sebesar 0,003, harga nilai t hitungnya sebesar 2.351 dengan tingkat signifikansi sebesar 0.001, promosi nilai t hitung sebesar 3.113 dengan tingkat signifikansi 0.004 dan distribusi nilai $\mathrm{t}$ hitung sebesar 3.063 dengan tingkat signifikansi 0.003 ( lebih kecil dari 0,05). Dengan demikian maka dapat dikatakan bahwa semua variabel bebas secara parsial mempunyai pengaruh yang signifikan terhadap terhadap Kepuasan Konsumen Produk Adeni di Kabupaten Pamekasan.

Kata Kunci : Kualitas Produk, Harga, Promosi, Distribusi dan Kepuasan Konsumen. 


\section{PENDAHULUAN}

Dewasa ini perusahaan air minum dalam kemasan semakin maju dengan pesat. Hal ini ditandai dengan meningkatnya jumlah konsumen air minum alam kemasan di Indonesia kususnya yang ada di Pamekasan. Di mana dari tahun ke tahun para semakin meningkat konsumen air minum alam kemasan serta bervariatif dengan berbagai macam bentuk dan model yang ditawarkan oleh para produsen konsumen air minum alam kemasan yang sesuai dengan keinginan rasa dan kebutuhan dari para konsumen dan calon konsumennya.

Di tengah keadaan perekonomian yang semakin sulit menyebabkan banyak terjadi persaingan di berbagai bidang kehidupan, salah satunya persaingan dalam dunia bisnis. Banyak perusahaan yang saling berlomba-lomba untuk mendapatkan pangsa pasarnya. Hal ini dapat memacu perusahaan untuk berusaha memperbaiki bisnisnya menjadi lebih maju. Di samping itu dengan adanya kemajuan teknologi, perusahaan dituntut pula untuk mengikuti perkembangan zaman agar tidak tertinggal dengan pesaingnya.

Dalam memenangkan keberhasilan suatu produk dari perusahaan itu, maka perusahaan harus menemukan cara jitu agar proses pemasarannya dapat berjalan dengan baik dan produk yang dihasilkan dapat dinyatakan berhasil. Reputasi serta kredibilitas mempunyai peranan yang sangat penting terhadap keberhasilan suatu produk. Untuk dapat sukses dipasaran produk harus mempunyai reputasi yang baik. Hal ini disebabkan kecenderungan konsumen yang menganggap bahwa produk yang mempunyai reputasi yang baik identik dengan produk yang berkualitas. Sekali perusahaan tersebut gagal mempertahankan reputasinya, ia akan kehilangan reputasinya dan untuk mendapatkan reputasinya itu maka perusahaan harus membayar dengan mahal baik materi maupun non materi.

Keputusan mengenai harga tidaklah mudah dilakukan. Disatu sisi, harga yang terlalu mahal dapat meningkatkan laba jangka pendek, tetapi disisi lain akan sulit dijangkau konsumen. Sedangkan bila harga terlalu murah, pangsa pasar dapat melonjak. Akan tetapi, marjin kontribusi dana laba bersih yang diperoleh dapat menjadi sangat kecil, bahkan tidak cukup untuk mendukung pertambahan atau ekspansi organisasi. Media promosi yang sering digunakan untuk menyampaikan informasi tentang produk adalah media periklanan. Periklanan merupakan salah satu media yang digunkakan perusahaan, bisa diklasifikasikan menurut tujuannya yaitu, untuk memberikan informasi, membujuk, dan mengingatkan.

Produsen atau perusahaan modern, kini menjauhi pemasaran masal dan pemasaran berbagai produk, dan mendekati pemasaran terarah. Penjual dapat mengembangkan produk yang tepat untuk setiap pasar sasaran dan menyesuaikan harga, saluran distribusi, dan iklannya untuk mencapai pasar sasaran secara efisien.

Kondisi persaingan yang ketat saat ini, menjadi hal utama yang perlu menjadi prioritas adalah bagaimana memberikan kepuasan kepada pelanggan agar tetap Loyal terhadap pruduk yang dikeluarkan oleh perusahaan, contohnya berupa air mineral dalam kemasan. salah satu perusahaan yang mengantisipasi kebutuhan air mineral dalam kemasan merk Adeni adalah Perusahaan Daerah Air Minum (PDAM) Kabupaten Pamekasan sebagai salah Badan Usaha Milik Daerah Kabupaten Pamekasan; Dengan harapan pelanggan menjadi loyal lagi, di mana nantinya digunakan oleh perusahaan untuk dapat bertahan, bersaing dan menguasai pangsa pasar yang ada. Manajemen harus mengetahui betul apa dan bagaimana keinginan para pelanggan dan bagaimana menghasilkan produk sebaik mungkin agar dapat memuaskan pelanggan, dalam hal ini sangatlah diperlukan adanya analisis faktor kepuasan pelanggan.

Air mineral dalam kemasan di masa yang akan datang semakin berat dalam mengelola bisnis air mineral, hal ini dikarenakan adanya para pesaing baru, dan banyak air mineral nasional yang bermunculan di Indonesia, sehingga tingkat persaingan cukup kompetitif. 
Dalam upaya untuk mempertahankan pangsa pasar dari para pesaing di segmen air mineral dalam kemasan, banyak kiat yang di Iakukan oleh perusahaan daerah air minum (PDAM) Kabupaten Pamekasan. Salah satu Iangkah yang ditempuh adaIah dengan mendeteksi kepuasan konsumen dari para pelanggan air mineral dalam kemasan merk Adeni di wilayah Pamekasan dan sekitarnya yang dipengaruhi oleh beberapa variabel yaitu :1. Kualitas roduk, 2. Harga 3. Promosi/Informasi dan 4.Distribusi.

\section{METODE PENELITIAN}

Jenis penelitian yang digunakan oleh peneliti adalah jenis penelitian eksplanasi. Penelitian eksplanasi adalah tingkat penjelasan, yaitu bagaimana variabel-variabel yang diteliti itu akan menjelaskan obyek yang diteliti melalui data yang terkumpul. Pengujian variabel penelitian dengan menggunakan analisis regresi, untuk mengetahui hubungan antara variabel terikat dengan variabel bebas yang digunakan dalam penelitian.

Populasi dalam penelitian ini adalah konsumen yang menjadi pelanggan Adeni di Kabupaten Pamekasan yang berjumlah 104 pelanggan.

Metode sampel yang digunakan dalam penelitian ini adalah metode sampel jenuh yaitu seluruh populasi penelitian digunakan sebagai sampel yaitu sebanyak 104 orang/konsumen. sampel jenuh adalah teknik penentuaan sampling bila semua anggota populasi digunakan sebagai sampel atau responden.

\section{HASIL DAN PEMBAHASAN}

Berdasarkan hasil penelitian diperoleh data bahwa kualitas produk (X1), harga (X2), promosi (X3), distribusi (X4) dan kepuasan konsumen (Y). Berikut ini merupakan hasil pengolahan data SPSS 17,0 mengenai diskripsi masing-masing variabel penelitian menurut persepsi responden dalam bentuk prosentase.

Tabel 4.5

Diskripsi Variabel X1

\begin{tabular}{|c|c|c|c|c|c|c|c|c|c|c|c|}
\hline \multirow{2}{*}{ No } & \multirow{2}{*}{ Item } & \multicolumn{2}{|c|}{ SS } & \multicolumn{2}{|c|}{ S } & \multicolumn{2}{c|}{ R } & \multicolumn{2}{c|}{ TS } & \multicolumn{2}{c|}{ STS } \\
\cline { 3 - 13 } & & S & $\%$ & S & $\%$ & S & $\%$ & S & $\%$ & S & $\%$ \\
\hline 1 & $(\mathrm{X} 1.1)$ & 32 & 30 & 62 & 59,6 & 10 & 9,6 & 0 & 0 & 0 & 0 \\
\hline 2 & $(\mathrm{X} 1.2)$ & 36 & 34,6 & 60 & 57,7 & 8 & 7,7 & 0 & 0 & 0 & 0 \\
\hline 3 & $(\mathrm{X} 1.3)$ & 33 & 31,7 & 67 & 64,4 & 4 & 3,8 & 0 & 0 & 0 & 0 \\
\hline
\end{tabular}

Berdasarkan Tabel 4.5 diatas dapat dijelaskan mengenai distribusi varibel kualitas produk (X1) sebagai berikut:

Item pernyataan pertama variabel kualitas produk adalah Penampilan produk air mineral dalam kemasan merk adeni yang dipasarkan sangat menarik. Berdasarkan hasil jawaban responden diketahui bahwa sebanyak 32 responden (30\%) menyatakan sangat setuju dan sebanyak 62 responden $(59,6 \%)$ menyatakan setuju dan sebanyak 10 responden $(9,6 \%)$ menyatakan ragu-ragu.

Item pernyataan kedua variabel kualitas produk adalah Kemasan air minum dalam kemasan merk Adeni sangat bagus Berdasarkan hasil jawaban responden diketahui bahwa sebanyak 36 responden $(34,6 \%)$ menyatakan sangat setuju, sebanyak 60 responden $(57,7 \%)$ menyatakan setuju dan sebanyak 8 responden $(7,7 \%)$ menyatakan ragu-ragu. 
Item pernyataan ketiga variabel kualitas produk adalah Isi air minum dalam kemasan merk Adeni jernih dan higienis. Berdasarkan hasil jawaban responden diketahui bahwa sebanyak 33 responden $(31,7 \%)$ menyatakan sangat setuju, sebanyak 67 responden $(64,4 \%)$ menyatakan setuju dan sebanyak 4 responden $(3,8 \%)$ menyatakan ragu-ragu.

Tabel 4.6

\section{Diskripsi Variabel X2}

\begin{tabular}{|c|c|c|c|c|c|c|c|c|c|c|c|}
\hline \multirow{2}{*}{ No } & \multirow{2}{*}{ Item } & \multicolumn{2}{|c|}{ SS } & \multicolumn{2}{|c|}{ S } & \multicolumn{2}{c|}{ R } & \multicolumn{2}{c|}{ TS } & \multicolumn{2}{c|}{ STS } \\
\cline { 3 - 13 } & & S & $\%$ & S & $\%$ & S & $\%$ & S & $\%$ & S & $\%$ \\
\hline 1 & $(\mathrm{X} 2.1)$ & 46 & 44,2 & 52 & 50 & 3 & 2,9 & 3 & 2,9 & 0 & 0 \\
\hline 2 & $(\mathrm{X} 2.2)$ & 53 & 51 & 51 & 49 & 0 & 0 & 0 & 0 & 0 & 0 \\
\hline 3 & $(\mathrm{X} 2.3)$ & 25 & 24 & 78 & 75 & 1 & 1 & 0 & 0 & 0 & 0 \\
\hline 4 & $(\mathrm{X} 2.4)$ & 33 & 31,7 & 71 & 68,3 & 0 & 0 & 0 & 0 & 0 & 0 \\
\hline
\end{tabular}

Sumber : Data primer diolah, 2015

Berdasarkan Tabel 4.6 diatas dapat dijelaskan mengenai distribusi varibel harga (X2) sebagai berikut :

Item pernyataan pertama variabel harga adalah Harga air minerall dalam kemasan merk adeni yang dipasarkan relative murah dan terjangkau. Berdasarkan hasil jawaban responden diketahui bahwa sebanyak 46 responden $(44,2 \%)$ menyatakan sangat setuju, sebanyak 52 responden (50\%) menyatakan setuju, sebanyak 3 responden $(2,9 \%)$ menyatakan ragu-ragu dan sebanyak 3 responden $(2,9 \%)$ menyatakan tidak setuju

Item pernyataan kedua variabel harga adalah Harga air minum dalam kemasan merk Adeni sesuai dengan manfaat yang diterima konsumen. Berdasarkan hasil jawaban responden diketahui bahwa sebanyak 51 responden (49\%) menyatakan sangat setuju dan sebanyak 53 responden (49\%) menyatakan setuju.

Item pernyataan ketiga variabel harga adalah Harga air minum dalam kemasan merk Adeni sesuai dengan manfaat yang diberikan perusahaan kepada konsumen Berdasarkan hasil jawaban responden diketahui bahwa sebanyak 25 responden (24\%) menyatakan sangat setuju, sebanyak 78 responden (75\%) menyatakan setuju dan sebanyak 1 responden (1\%) menyatakan ragu-ragu.

Item pernyataan keempat variabel harga Perusahaan senantiasa memberikan discount pada setiap transaksi tertentu. Berdasarkan hasil jawaban responden diketahui bahwa sebanyak 33 responden (31,7\%) menyatakan sangat setuju dan sebanyak 71 responden $(68,3 \%)$ menyatakan setuju.

Tabel 4.7

Diskripsi Variabel X3

\begin{tabular}{|c|c|c|l|c|c|c|c|c|c|c|c|}
\hline \multirow{2}{*}{ No } & \multirow{2}{*}{ Item } & \multicolumn{2}{|c|}{ SS } & \multicolumn{2}{|c|}{ S } & \multicolumn{2}{c|}{ R } & \multicolumn{2}{c|}{ TS } & \multicolumn{2}{c|}{ STS } \\
\cline { 3 - 13 } & & S & $\%$ & S & $\%$ & S & $\%$ & S & $\%$ & S & $\%$ \\
\hline 1 & $(X 3.1)$ & 41 & 39,4 & 0 & 0 & 0 & 0 & 0 & 0 & 0 & 0 \\
\hline
\end{tabular}




\begin{tabular}{|c|c|c|c|c|c|c|c|c|c|c|c|}
2 & $(\mathrm{X} 3.2)$ & 63 & 60,6 & 0 & 0 & 0 & 0 & 0 & 0 & 0 & 0 \\
\hline 3 & (X3.3) & 28 & 26,9 & 76 & 73,1 & 0 & 0 & 0 & 0 & 0 & 0 \\
\hline 4 & (X3.4) & 42 & 40,4 & 62 & 59,6 & 0 & 0 & 0 & 0 & 0 & 0 \\
\hline
\end{tabular}

Sumber : Data primer diolah, 2015

Berdasarkan Tabel 4.7 diatas dapat dijelaskan mengenai distribusi varibel promosi (X3) sebagai berikut :

Item pernyataan pertama variabel promosi adalah Kemudahan memperoleh informasi /romosi perkaitan produk AMDK merk Adeni. Berdasarkan hasil jawaban responden diketahui bahwa sebanyak 41 responden $(39,4 \%)$ menyatakan sangat setuju dan sebanyak 63 responden $(60,6 \%)$ menyatakan setuju.

Item pernyataan kedua variabel promosi adalah Perusahaan Adeni senantiasa memberikan pelayanan yang baik terhadap kosumen/pelanggan. Berdasarkan hasil jawaban responden diketahui bahwa sebanyak 28 responden $(26,9 \%$,) menyatakan sangat setuju dan sebanyak 76 responden $(73,1 \%)$ menyatakan setuju.

Item pernyataan ketiga variabel promosi adalah Perusahaan AMDK merk Adeni senantiasa menguamakan kualitas pelayanan yang baik terhadap konsumennya/pelanggan. Berdasarkan hasil jawaban responden diketahui bahwa sebanyak 42 responden (40,4\%) menyatakan sangat setuju dan sebanyak 62 responden $(59,6 \%)$ menyatakan setuju.

Tabel 4.8

\section{Diskripsi Variabel X4}

\begin{tabular}{|c|c|c|l|l|l|l|l|l|l|l|l|}
\hline \multirow{2}{*}{ No } & \multirow{2}{*}{ Item } & \multicolumn{2}{|c|}{ SS } & \multicolumn{2}{|c|}{ S } & \multicolumn{2}{c|}{ R } & \multicolumn{2}{c|}{ TS } & \multicolumn{2}{c|}{ STS } \\
\cline { 3 - 13 } & & S & $\mathbf{\%}$ & S & \% & S & \% & S & $\%$ & S & $\%$ \\
\hline 1 & $(\mathrm{X} 4.1)$ & 49 & 47,1 & 29 & 27,9 & 26 & 25 & 0 & 0 & 0 & 0 \\
\hline 2 & $(\mathrm{X} 4.2)$ & 28 & 26,9 & 53 & 51 & 23 & 22,1 & 0 & 0 & 0 & 0 \\
\hline 3 & $(\mathrm{X} 4.3)$ & 33 & 31,7 & 46 & 44,2 & 16 & 15,4 & 9 & 8,7 & 0 & 0 \\
\hline
\end{tabular}

Sumber : Data primer diolah, 2015

Berdasarkan Tabel 4.8 diatas dapat dijelaskan mengenai distribusi varibel pengembangan distribusi (X4) sebagai berikut :

Item pernyataan pertama variabel distribusi adalah Produk AMDK merk Adeni selalu tersedia di super market/ mini market/ took tradisional. Berdasarkan hasil jawaban responden diketahui bahwa sebanyak 49 responden $(47,1 \%)$ menyatakan sangat setuju, sebanyak 29 responden $(27,9 \%)$ menyatakan setuju dan sebanyak 26 responden $(25 \%)$ menyatakan ragu-ragu.

Item pernyataan kedua variabel distribusi adalah Pengadaan/ distribudi item produk Adeni kepada pelanggan selalu tepat waktu. Berdasarkan hasil jawaban responden diketahui bahwa sebanyak 28 responden $(26,9 \%$,) menyatakan sangat setuju, sebanyak 53 responden (51\%) menyatakan setuju dan sebanyak 23 responden (22,1\%) menyatakan ragu-ragu.

Item pernyataan ketiga variabel distribusi adalah Distribusi produk Adeni sangat lancar dan membantu konsumen. Berdasarkan hasil jawaban responden diketahui bahwa sebanyak 33 responden $(31,7 \%)$ menyatakan sangat setuju, sebanyak 46 responden $(44,2 \%)$ 

menyatakan setuju, sebanyak 16 responden $(15,4 \%)$ menyatakan ragu-ragu dan sebanyak 9 responden $(8,7 \%)$ menyatakan tidak setuju.

Tabel 4.9

Deskripsi Variabel Y

\begin{tabular}{|c|c|c|l|l|l|l|l|l|l|l|l|}
\hline \multirow{2}{*}{ No } & \multirow{2}{*}{ Item } & \multicolumn{2}{|c|}{ SS } & \multicolumn{2}{c|}{ S } & \multicolumn{2}{c|}{ R } & \multicolumn{2}{c|}{ TS } & \multicolumn{2}{c|}{ STS } \\
\cline { 3 - 13 } & & S & $\%$ & S & \% & S & \% & S & $\%$ & S & $\%$ \\
\hline 1 & (Y.1) & 49 & 47,1 & 29 & 27,9 & 26 & 25 & 0 & 0 & 0 & 0 \\
\hline 2 & (Y.2) & 28 & 26,9 & 53 & 51 & 23 & 22,1 & 0 & 0 & 0 & 0 \\
\hline 3 & (Y.3) & 28 & 26,9 & 76 & 73,1 & 0 & 0 & 0 & 0 & 0 & 0 \\
\hline 4 & (Y.4) & 25 & 24 & 78 & 75 & 1 & 1 & 0 & 0 & 0 & 0 \\
\hline
\end{tabular}

Berdasarkan Tabel 4.9 diatas dapat dijelaskan mengenai distribusi varibel kepuasan konsumen (Y) sebagai berikut :

Item pernyataan pertama variabel kepuasan konsumen adalah Kualitas Adeni didasarkan pada mutu/ keunggulan yang ideal. Berdasarkan hasil jawaban responden diketahui bahwa sebanyak 49 responden $(47,1 \%)$ menyatakan sangat setuju, sebanyak 29 responden $(27,9 \%)$ menyatakan setuju dan sebanyak 26 responden $(25 \%)$ menyatakan ragu-ragu.

Item pernyataan kedua variabel kepuasan konsumen adalah Manfaat produk AMDK merk Adeni sesuai keinginan konsumen. Berdasarkan hasil jawaban responden diketahui bahwa sebanyak 28 responden (26,9\%,) menyatakan sangat setuju, sebanyak 53 responden (51\%) menyatakan setuju dan sebanyak 23 responden (22,1\%) menyatakan ragu-ragu.

Item pernyataan ketiga variabel kepuasan konsumen adalah Kuantitas Adeni sesuai dengan harapan konsumen. Berdasarkan hasil jawaban responden diketahui bahwa sebanyak 28 responden $(26,9 \%)$ menyatakan sangat setuju dan sebanyak 76 responden $(73,1 \%)$ menyatakan setuju.

Item pernyataan keempat variabel kepuasan konsumen adalah Diskon yang diberikan perusahaan kepada konsumen sangat kompetitif. Berdasarkan hasil jawaban responden diketahui bahwa sebanyak 25 responden (24\%) menyatakan sangat setuju, sebanyak 78 responden $(75 \%)$ menyatakan setuju dan sebanyak 1 responden (1\%) menyatakan raguragu.

\section{PENUTUP}

\section{Kesimpulan}

Berdasarkan hasil analisis data serta pembahasan di bab sebelumnya, maka kesimpulan penelitian ini adalah :

1. Secara simultan, kualitas produk, harga, promosi dan distribusi mempunyai pengaruh yang signifikan terhadap kepuasan konsumen produk Adeni di Kabupaten Pamekasan.

2. Secara parsial, kualitas produk, harga, promosi dan distribusi mempunyai pengaruh yang signifikan terhadap kepuasan konsumen produk Adeni di Kabupaten Pamekasan.

3. Berdasarkan dari hasil uji t tersebut, maka diketahui bahwa kualitas produk mempunyai pengaruh dominan terhadap kepuasan konsumen produk Adeni di Kabupaten Pamekasan. 


\section{DAFTAR PUSTAKA}

Arikunto, Suharsimi. 2008. Prosedur Penelitian. Jakarta : PT. Rineka Cipta.

Assael, Henry, 2002. Consumer Behaviour and Marketing Action.Thirth Edition. Kent Publishing Company. Boston.

Engel James, Roger D. Blacwell, Paul W. Minird, 2004.Perilaku Konsumen, Alih Bahasa oleh FX. Budiyanto, Cetakan ketiga, Binapura Aksara, Jakarta.

Ferrel P, 2005, Pemasaran Teori \& Praktek Sehari - hari. Cetakan Pertama, Birmpura Aksara, Jakarta.

Kotler, 2004, Marketing Management : Analisys, Planning, Implementation And Control; 8 th ed. Enlewood Cliffs. N.J; Prentice Hall International, lnc.

Kotler, 2007, Manajemen pamasaran Analisys, Perencanaan, Implementasi dan Kontrol., edisi Ketujuh, Penerbit PT. Prehallindo, Jakarta.

Levitt, 2002, Imajinasi Pemasaran 9 (terjemahan) Jakarta. Penerbit

Erlangga Parwitra, 2003, Pemasaran : Dimensi Falsafah, Disiplin dan Keahlian. Jakarta. Sekolah Tinggi Prasetya Mulya.

Philip Kotler, gary Amstrong, 2006,Principles Of Markting, Twelfith Edition, Published by Pearson Eductian, Inc.

Tjiptono,2007, Strategi pemasaran Edisi II. Penerbit Andi Yogyakarta.

Umar Hussein, 2009, Metodologi Penelitian, Cetakan ketiga,

PT. Gramedia Pustaka.

W. Cravens David, 2006, Pemasaran Strategis, Cetakan ketga, penerbit Airlangga Jakarta.

Santoso, 2000, Latihan SPSS Statistik Parametrik Cetakan ketiga

PT. Elex Media Kompetido

Sugiyono. 2007. Statistika Untuk Penelitian. Bandung: Alfabeta

Santoso, 2000, Latihan SPSS Statistik Parametrik Cetakan ketiga

PT. Elex Media Kompetido

Sugiyono. 2007. Statistika Untuk Penelitian. Bandung: Alfabeta 